\title{
Effects of Obesity on the Auditory Function of Children and Adolescents
}

\author{
Engin Başer ${ }^{10}$ Havva Nur Peltek Kendirci ${ }^{2}$ (1) \\ ${ }^{1}$ Department of Otorhinolaryngology, Head and Neck Surgery, \\ University of Health Sciences, Izmir Tepecik Training and Research \\ Hospital, İzmir, Turkey \\ ${ }^{2}$ Department of Pediartic Endocrinology, Hitit University, Faculty of \\ Medicine, Corum, Turkey
}

\begin{abstract}
Address for correspondence Engin Başer, Assoc. Prof., Department of Otorhinolaryngology, Head and Neck Surgery, University of Health Sciences, Izmir Tepecik Training and Research Hospital, Yenisehir, Gaziler Street, $N^{\circ} 468$, Konak, İzmir, Turkey

(e-mail: dr.enginbaser@hotmail.com).
\end{abstract}

Int Arch Otorhinolaryngol 2022;26(3):e440-e445.

\begin{abstract}
Keywords

- childhood

- adolescent

- obesity

- pure-tone audiometry

- speech audiometry

Introduction Childhood and adolescent obesity is associated with insulin resistance, abnormal glucose metabolism, hypertension, dyslipidemia, inflammation, liver disease, and compromised vascular function.

Objective We aimed to evaluate the effects of obesity on the auditory function and speech audiometry of children and adolescents.

Methods Subjects with a body mass index (BMI) higher than +2 standard deviation (SD) were classified as obese, and subjects with normal BMI SD were classified as the control group. Blood samples were taken for glucose, insulin, and lipid profiles following an 8-hour fasting period, and a hepatobiliary ultrasound was performed. The homeostatic model assessment for insulin resistance (HOMA-IR) was calculated. The audiological evaluation included pure-tone audiometry (PTA), speech reception threshold (SRT), and speech discrimination score (SDS).

Results The study included 100 children (50 girls) with obesity, with a mean age of $11.4 \pm 2.9$ years and 30 children with normal body weight, with a mean age of $11.9 \pm 3.3$ years. Of the children with obesity, $55 \%(n=55)$ were found to have hyperlipidemia, $68 \%(n=68)$ insulin resistance, and $21 \%(n=21)$ hepatosteatosis. There were no statistically significant differences between children with obesity and the control group in terms of SDS or PTA, while SRT was found to be higher in children with obesity. There was no difference between obese children with or without hyperlipidemia, between obese children with or without insulin resistance, and between obese children with or without hepatosteatosis, according to hearing tests. Conclusion The result of the present study indicates that children with obesity are more prone to having auditory problems than the normal population. We recommend more frequent audiological evaluations, including speech audiometry, in children and adolescents with obesity problems
\end{abstract}

received

September 2, 2020 accepted after revision

March 23, 2021

published online

January 24, 2022
DOI https://doi.org/ 10.1055/s-0041-1739312. ISSN 1809-9777.

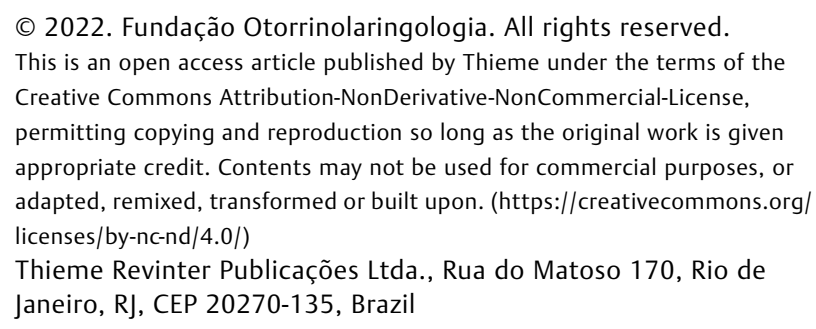

(c) 2022. Fundação Otorrinolaringologia. All rights reserved. This is an open access article published by Thieme under the terms of the Creative Commons Attribution-NonDerivative-NonCommercial-License, permitting copying and reproduction so long as the original work is given appropriate credit. Contents may not be used for commercial purposes, or adapted, remixed, transformed or built upon. (https://creativecommons.org/ licenses/by-nc-nd/4.0/) Thieme Revinter Publicações Ltda., Rua do Matoso 170, Rio de Janeiro, RJ, CEP 20270-135, Brazil 


\section{Introduction}

Pediatric obesity is one of the most serious global health problems of this century. Obesity occurring in childhood may lead to several complex metabolic complications, including increased insulin resistance, diabetes, respiratory problems, musculoskeletal system disorders, and predisposition to certain forms of cancer, as well as cardiovascular complications, and the psychological effects of low self-esteem, low academic achievement, and depression. ${ }^{1,2}$ In addition, it is reported that obesity starting in childhood is more harmful than obesity starting in adulthood. ${ }^{3}$

In recent years, the relationship between obesity and hearing loss has attracted the attention of researchers. The cochlear hair cells of the inner ear are fundamental receptors in hearing function. Mature mammalian cochlear hair cells are unable to regenerate. Therefore, damage to these cells results in permanent hearing loss. ${ }^{2}$ In a few studies performed through microvascular circulation mechanisms of the cochlea, obesity was defined as a predisposing factor for hearing loss. ${ }^{4}$ It is known that obesity causes dysfunction in many organs and sensorial systems of the body via oxidative stress and lipotoxicity. 5 Many comorbid conditions, such as metabolic, cardiovascular, orthopedic, neurological, hepatic, pulmonary, and renal disorders, have been associated with childhood obesity. Until recently, many of the aforementioned health conditions had only been observed in adults, whereas now they are extremely prevalent in obese children. Childhood obesity is also associated with poor academic performance and the child experiencing lower quality of life. ${ }^{6}$ Since individuals with hearing loss also experience communication loss, in addition to other obesity-related comorbidities, this condition may increase obesity much more by leading to social regression. Obesity and hearing loss considerably reduce both physical and psychological quality of life ${ }^{7}$.

We believe that the effect of obesity and its comorbidities starting in childhood, which is an important stage of cognitive development, on hearing has not been examined as much as it deserves in the literature. We aimed to evaluate the effects of obesity on the auditory function and speech audiometry of children and adolescents as well as to investigate the relationships between audiological parameters and comorbidities such as insulin resistance, dyslipidemia, and hepatosteatosis in obese children.

\section{Methods}

The study protocol was approved by the local ethics committee (Approval number: 108400987-281). Written informed consent was obtained from the parents at the start of the study in accordance with the Declaration of Helsinki.

\section{Study Procedures}

A total of 100 obese children and adolescents between the ages of 5 and 17 with a BMI $>95 \%$ who presented to the pediatric endocrinology outpatient clinic between May and October 2014 and who were cooperative when undertaking audiometric examination were included in the study. Thirty children and adolescents with a normal body weight who underwent audiometry for school screening and were agegender matched with the patient group constituted the control group. The children and adolescents with a type A tympanogram results and normal otorhinolaryngological examination results, and without comorbid systemic disease, without history of use of ototoxic medications, without acoustic and/or physical trauma, or without history of hearing loss in the family were included in the study. Children and adolescents with syndromic obesity, known hearing disorder, familial hearing loss, upper respiratory tract infection within the last 3 months, prominent hypertrophy of adenoid tissue with or without tonsil enlargement, and tympanic membrane perforation or cicatricial stricture were excluded from the study.

Following overnight fasting, venous blood samples were collected for the measurement of serum levels of triglycerides, cholesterol, insulin, and glucose. Insulin resistance was assessed with the homeostasis model assessment of insulin resistance (HOMA-IR), which was calculated by using the following formula: [fasting insulin $(\mu \mathrm{U} / \mathrm{L}) \mathrm{x}$ fasting glucose level $(\mathrm{mmol} / \mathrm{L}) / 22.5]$. Liver ultrasound was performed in all patients.

A value of HOMA-IR $>2.5$ in prepubertal children and $>3.1$ in pubertal children and adolescents was defined as insulin resistance. ${ }^{8}$ The definition of dyslipidemia was made according to the triglyceride and high-density lipoprotein (HDL)-cholesterol levels in - Table $1^{9}$.

\section{Hearing Evaluation}

Audiometry tests were performed in a sound-treated room and at frequencies of $125-8,000 \mathrm{~Hz}$. Pure tone average (PTA), speech reception threshold (SRT), and speech discrimination scores (SDS) were measured at frequencies of 250, 500, $1,000,2,000,4,000$, and $8,000 \mathrm{~Hz}$. Pure tone average was calculated by averaging measurements at 500, 1,000, 2,000, and $4,000 \mathrm{~Hz}$. Speech discrimination score was evaluated with monosyllabic words. Audiometric evaluations were

Table 1 The definition of dyslipidemia

\begin{tabular}{|l|l|l|l|l|l|l|}
\hline & \multicolumn{3}{|l|}{$5-9$ years old } & \multicolumn{2}{l|}{ 10-14 years old } & \multicolumn{2}{l|}{ 15-18 years old } \\
\cline { 2 - 7 } & Boy & Girl & Boy & Girl & Boy & Girl \\
\hline HDL-cholesterol $(\mathrm{mg} / \mathrm{dl})$ & $<42$ & $<38$ & $<40$ & $<40$ & $<34$ & $<38$ \\
\hline Triglyceride $(\mathrm{mg} / \mathrm{dl})$ & $>85$ & $>126$ & $>115$ & $>120$ & $>143$ & $>126$ \\
\hline
\end{tabular}

Abbreviation: HDL, high-density lipoprotein. 
performed by a single senior audiometrist. Physical examinations of the patients were performed by the same otorhinolaryngologist and pediatric endocrinologist.

\section{Statistical Analysis}

The IBM SPSS Statistics for Windows Version 22.0 software (IBM Corp., Armonk, NY, USA) was used for statistical analysis. Descriptive statistics of the variables studied were presented as mean and standard deviation (SD) for continuous variables. Descriptive statistics of categorical variables were expressed as counts and percentages. Skewness and kurtosis tests were used to determine whether or not data were normally distributed. The Student $t$-test was used for intergroup comparisons of variables with normal distribution. A $p$-value of $<0.05$ was considered to be statistically significant.

\section{Results}

The present study included 100 obese children ( 50 girls) with a mean age of $11.4 \pm 2.9$ years, and 30 children ( 15 girls) with a normal body weight and a mean age of $11.9 \pm 3.3$ years. Seventy-five percent $(n=75)$ of obese subjects and $66.7 \%$ $(n=20)$ of non-obese subjects were determined to be within the pubertal period. No difference was determined between groups regarding age, gender distribution, height, height SDS, and pubertal stage. The clinical characteristics of groups are shown in - Table 2.

It was observed that $55 \%(n=55), 68 \%(n=68)$, and $21 \%$ $(n=21)$ of obese children were determined to have hyperlipidemia, insulin resistance, and hepatosteatosis, respec-

Table 2 Clinical characteristics of the subjects (mean \pm SD) (min-max) (mean)

\begin{tabular}{|l|l|l|l|}
\hline & $\begin{array}{l}\text { Obese group } \\
(\boldsymbol{n}=\mathbf{1 0 0})\end{array}$ & $\begin{array}{l}\text { Control group } \\
(\boldsymbol{n}=\mathbf{3 0})\end{array}$ & $\boldsymbol{P}$ \\
\hline Age (years) & $\begin{array}{l}11.4 \pm 2.9 \\
(5.4-17.7)\end{array}$ & $\begin{array}{l}11.9 \pm 3.3 \\
(6.3-17.9)\end{array}$ & 0.38 \\
\hline Weight $(\mathrm{kg})$ & $\begin{array}{l}66.2 \pm 19.2 \\
(29.0-113.8)\end{array}$ & $\begin{array}{l}43.0 \pm 15.9 \\
(18-69)\end{array}$ & 0.00 \\
\hline Weight SDS & $\begin{array}{l}2.7 \pm 0.7 \\
(1.0-5.3)\end{array}$ & $\begin{array}{l}-0.2 \pm 0.9 \\
(-1.9-1.6)\end{array}$ & 0.00 \\
\hline Height (cm) & $\begin{array}{l}149.2 \pm 14.0 \\
(117.5-183.6)\end{array}$ & $\begin{array}{l}150.0 \pm 18.6 \\
(110.0-177.2)\end{array}$ & 0.70 \\
\hline Height SDS & $\begin{array}{l}0.64 \pm 1.29 \\
(-2.9-4.9)\end{array}$ & $\begin{array}{l}0.21 \pm 0.83 \\
(-2.0-1.66)\end{array}$ & 0.09 \\
\hline BMI (kg/m $\left.{ }^{2}\right)$ & $\begin{array}{l}29.0 \pm 4.1 \\
(20.4-45.8)\end{array}$ & $\begin{array}{l}18.1 \pm 3.2 \\
(12.9-24.0)\end{array}$ & 0.00 \\
\hline BMI SDS & $\begin{array}{l}2.6 \pm 0.4 \\
(2.0-4.0)\end{array}$ & $-0.39 \pm 1.0$ & 0.00 \\
& $(-2.2-1.4)$ & \\
\hline $\begin{array}{l}\text { Puberty } \\
\text { (mean) }\end{array}$ & $\begin{array}{l}3 \\
1-5\end{array}$ & 0.97 \\
\hline
\end{tabular}

Abbreviations: BMI, body mass index; cm, centimeters; kg, kilograms; $n$, number; SD, standard deviation; SDS, speech discrimination score.
Table 3 Laboratory features of obese children

\begin{tabular}{|l|l|l|l|}
\hline & Mean \pm SD & Min & Max \\
\hline Cholesterol $(\mathrm{mg} / \mathrm{dL})$ & $176.8 \pm 31.1$ & 106.0 & 243.0 \\
\hline Triglyceride $(\mathrm{mg} / \mathrm{dL})$ & $119.2 \pm 62.2$ & 34 & 385 \\
\hline HDL $(\mathrm{mg} / \mathrm{dL})$ & $41.7 \pm 10.1$ & 21 & 68 \\
\hline LDL $(\mathrm{mg} / \mathrm{dL})$ & $100.9 \pm 23.7$ & 56 & 151 \\
\hline VLDL $(\mathrm{mg} / \mathrm{dL})$ & $33.9 \pm 11.5$ & 5 & 64 \\
\hline HOMA-IR & $4.7 \pm 2.8$ & 1.6 & 14.4 \\
\hline
\end{tabular}

Abbreviations: HDL, high-density lipoprotein; HOMA-IR, homeostatic model assessment for insulin resistance; LDL, low-density lipoprotein; SD, standard deviation; VLDL, very low-density lipoprotein.

tively. The laboratory results of obese children are shown in - Table 3.

No statistical difference was determined between obese female children $(n=50)$ and obese male children $(n=50)$ in terms of age, weight, weight SD, height, height standard deviation (SD), BMI, and BMI SD. It was determined that $10 \%$ of female children were in the prepubertal period, while $40 \%$ of male children were in the prepubertal period and this difference was statistically significant $(p=0.001)$. There was no difference between female and male children in regards to the presence of hyperlipidemia, insulin resistance, and hepatosteatosis. No difference was determined between female and male children regarding any of the hearing tests $(p>0.05)$.

No difference was determined between groups with and without hyperlipidemia, with and without insulin resistance regarding hearing tests $(p>0.05)$.

The prevalence of hyperlipidemia and hyperinsulinemia was found to be higher in the hepatosteatosis group ( $p=0.018, p=0.021$, respectively). While there was no difference between obese subjects with and without hepatosteatosis according to PTA and SDS values $(p=0.399$, $p=0.555$, respectively), SRT values were determined to be significantly higher in the hepatosteatosis group $(p=0.046)$.

There was no difference between obese children and control groups in terms of SDS, and PTA, while SRT was found to be higher in children with obesity (-Table 4 ).

\section{Discussion}

Obesity and concomitant comorbid disorders can affect many sensory systems and organs. Pediatric screenings of hearing to identify possible hearing loss and improve loss of quality of life are conducted in school-aged children up to adolescence in many developed countries. PTA, today's standard in the assessment of hearing, is unsuitable for evaluating its most important attribute of hearing, its cognitive aspect. ${ }^{10}$ Speech discrimination scores and SRT are more important, considering the development of speech and language, especially in a noisy classroom environment. It may be important to evaluate the effect of obesity, which can be accompanied by many comorbid diseases, on hearing functions in the pediatric-adolescent age group. Therefore, we 
Table 4 Hearing tests of obese subjects and control group $($ mean \pm SD) $(\min -\max )$

\begin{tabular}{|l|l|l|l|l|}
\hline \multicolumn{2}{|c|}{} & $\begin{array}{l}\text { Obese group } \\
(\boldsymbol{n}=100)\end{array}$ & $\begin{array}{l}\text { Control group } \\
(\boldsymbol{n}=30)\end{array}$ & $P$ \\
\hline \multirow{2}{*}{ PTA } & Right & $\begin{array}{l}7.9 \pm 3.5 \\
(2-21)\end{array}$ & $\begin{array}{l}7.4 \pm 3.0 \\
(5.0-18.0)\end{array}$ & 0.51 \\
\cline { 2 - 5 } & Left & $\begin{array}{l}7.7 \pm 4.0 \\
(2-28)\end{array}$ & $\begin{array}{l}7.7 \pm 3.5 \\
(4.0-20.0)\end{array}$ & 0.95 \\
\hline SRT & Right & $\begin{array}{l}17.1 \pm 4.9 \\
(10-35)\end{array}$ & $\begin{array}{l}14.0 \pm 4.1 \\
(5.0-25.0)\end{array}$ & 0.002 \\
\cline { 2 - 5 } & Left & $\begin{array}{l}17.0 \pm 5.0 \\
(10-35)\end{array}$ & $\begin{array}{l}14.5 \pm 5.0 \\
(5.0-30.0)\end{array}$ & 0.01 \\
\hline SDS & Right & $\begin{array}{l}90.9 \pm 5.6 \\
(76-100)\end{array}$ & $\begin{array}{l}92.2 \pm 5.6 \\
(80.0-100.0)\end{array}$ & 0.26 \\
\cline { 2 - 5 } & Left & $\begin{array}{l}91.7 \pm 5.5 \\
(76-100)\end{array}$ & $\begin{array}{l}92.1 \pm 5.1 \\
(84.0-100.0)\end{array}$ & 0.18 \\
\hline
\end{tabular}

Abbreviations: PTA, pure tone average; SDS, speech discrimination score; SRT, speech reception threshold.

aimed to evaluate the effect of childhood obesity on cochlear functions and neurological pathways by using PTA, SDS, and SRT.

In studies investigating the effects of obesity on the hearing function, results varied according to age groups ${ }^{11}$. In a study evaluating adults, a positive relationship was observed between high BMI and hearing thresholds and a similar effect was seen at all frequencies. ${ }^{12}$ Lalwani et al. reported that obesity in adolescents aged 12 to 19 years was associated with sensorineural hearing loss (SNHL) at low frequencies; they found that obesity was associated with a 1.85 fold increase in SNHL, with age and gender being irrelevant. $^{13}$ Moore et.al., reported that PTA did not vary substantially depending on cognitive ability, but SRT depended strongly on cognitive performance. ${ }^{10}$ We determined that PTA was not affected at all frequencies. However, SRT was higher $(p<0.05)$ and SDS was lower $(p>0.05)$ in obese subjects. Considering these high SRT and low SDS values, we believe that obese children and adolescents may have a higher risk of developmental delay in speech and language, leading to learning problems. For this reason, SDS and SRT should be added to follow-up of obese children.

Many studies have observed that the relationship between obesity and hearing loss was stronger in females, when compared with males ${ }^{7}$. Shargorodsky et al. concluded that obesity was not a risk factor for hearing loss in male subjects aged 40 to 74 years. ${ }^{14}$ Kim et al. determined that there was a positive relationship between PTA and visceral adipose tissue in adult women. ${ }^{15}$ Hwang et al. reported that obesity was associated with hearing loss for high frequencies in female subjects older than 55 and for both low and high frequencies in males younger than $55 .^{11}$ Similarly, Ucler et al. also concluded that auditory thresholds were elevated at high frequencies in obese adult females. ${ }^{5}$ In our study, no difference was determined between female and male subjects, according to hearing tests. This implies that genderrelated difference in the association between obesity and hearing functions becomes more pronounced with increasing age.

Although different hypotheses have been suggested regarding the relationship between obesity and hearing loss, the main cause is vasoconstriction in the inner ear ${ }^{7}$. Since the cochlea is a very metabolically active organ, its vascularization and oxygenation are important ${ }^{5}$. Hwank et al. demonstrated that hearing threshold levels at high frequencies were elevated in mice with diet-induced obesity. In the histological study, constricted blood vessels were observed in the stria vascularis part of the cochlea ${ }^{16}$. Moreover, high BMI and dyslipidemia lead to narrowing of arteries and decreased blood flow by causing atherosclerotic vascular disease $^{17,18}$. Adipose tissue affects insulin resistance, energy metabolism, and atherosclerosis through the release of hormones and cytokines, and it may exacerbate inflammation and end-organ damage caused by obesity. Obesity directly leads to worsening of hearing through lipotoxicity and related oxidative stress or indirectly contributes to peripheral hearing degeneration via its comorbidity-related angiopathy and/or neuropathy ${ }^{19}$.

Satar et al. reported that dyslipidemia could cause cochlear injury by leading to edema in the outer hair cells and the stria vascularis. ${ }^{20}$ Lee et al. emphasized that elevated total cholesterol and triglyceride (TG) levels, and increased BMI were associated with increased prevalence of SNHL, which occurred as a result of damage due to cochlear ischemia. ${ }^{21}$ Shargorodsky et al. reported that hypercholesterolemia was associated with increased risk of hearing loss in adult males. ${ }^{14}$ Evans et al. reported that chronic dyslipidemia associated with elevated TG levels may reduce hearing function. ${ }^{22}$ In the study performed by Frederiksen et al., while a strong association was determined between high TG, high BMI, and high HDL levels and hearing loss, there was no association between low-density lipoprotein (LDL) levels and hearing loss. ${ }^{17}$ Nevertheless, there are also studies that report a weak association between serum lipid levels and hearing loss. ${ }^{23}$ We determined no difference between children/adolescents with and without hyperlipidemia regarding hearing tests. The fact that hyperlipidemia-related auditory function is unaffected in the young population suggests that the duration of exposure may affect auditory function as much as hyperlipidemia itself.

Zivkovic-Marinkov et al. conducted a study on hearing loss in adult patients with type 2 diabetes and reported that patients with type 2 diabetes had significantly impaired hearing compared with the control group, also suggesting that prolongation of poorly-controlled glycemia exacerbated hearing loss. ${ }^{24,25}$ Kilic et al. investigated the effects of metabolic syndrome on hearing functions, and observed that children with metabolic syndrome had higher hearing thresholds, especially at low frequencies. ${ }^{2}$ To the best of our knowledge, there is no study investigating the effect of isolated insulin resistance on auditory functions. In our study, we determined no difference between obese children/adolescents with and without insulin resistance regarding hearing tests. Since it does not impair glycemic control, insulin resistance may not affect hearing tests. 
Healthy hearing depends on sensitive ears and adequate brain processing. ${ }^{10}$ The relationship between obesity and increase in speech threshold may be due to impaired cognitive functions. Childhood obesity is related to decrease in executive function, attention, mental rotation, mathematics, and reading achievement. Obese adolescents have deficits in a range of cognitive functions, such as attention and executive functions. ${ }^{26}$ Impairment of audiological parameters, as mentioned by many studies, may be due to decrease in cognitive function besides the microvascular circulatory disorder at the cochlear level. This should be exposed with large and comprehensive studies.

Language skills are also important determinants of daily functioning and health and are closely linked to academic and employment outcomes. ${ }^{27}$ Speech perception (measured as SRT) develops rapidly toward adolescence and then more slowly until it plateaus in mid-adulthood, before declining at $\sim 60$ years of age. ${ }^{28}$ Changes in hearing during childhood and adolescence can be neglected by the families and physicians, and this condition may adversely affect the social development, academic performance, and cognitive functions of children. It should be kept in mind that negative social and cognitive outcomes resulting from hearing loss may exacerbate the clinical manifestation of obesity in individuals even further. The struggle against obesity, especially in childhood, is critical to the social and intellectual health of society. According to our results, we believe that hearing evaluation with speech audiometry is necessary, regardless of the etiology of hearing impairment, such as microvascular circulation imbalance, psychosocial effects, and cognitive dysfunction. Moreover, audiologic follow-up should be conducted more frequently than in the normal childhood hearing screening program.

The present study has several limitations. First, the number of patients in our group was not large. Secondly, our study had a cross-sectional design. For this reason, we were unable to evaluate the auditory functions and speech audiometry of our subjects in the long term. The tests were also subjective. Therefore, additional long-term prospective studies with a greater number of patient and control groups are required.

\section{Conclusion}

Obesity in childhood is associated with higher SRT and lower SDS. We suggest that audiological functions (with speech audiometry) should be followed up more frequently in obese children and adolescents.

\section{Informed Consent}

"Informed consent was obtained from all individual participants included in the study." Written consent was taken from the parents at the beginning of the study, in accordance with the Declaration of Helsinki.

Financial Disclosure

No financial disclosure.

\section{Conflict of Interests}

The authors declare that they have no conflict of interests.

\section{References}

1 Moxley E, Habtzghi D, Klinkhamer N, Wang H, Donnelly S, Dykhuizen J. Prevention and Treatment of Pediatric Obesity: A Strategy Involving Children, Adolescents and the Family for Improved Body Composition. J Pediatr Nurs 2019;45:13-19 https://linkinghub.elsevier.com/retrieve/pii/S088259631830 3658 cited 2019Jul15 [Internet]

2 Kilic K, Sakat MS, Cayir A. Evaluation of Hearing in Children with Metabolic Syndrome. Turk Otolarengoloji Arsivi/Turkish Arch Otolaryngol [Internet] 2018;56(03):160-5 Available from: http:// www.turkarchotolaryngol.net/eng/makale/736/78/Full-Text

3 Lobstein T, Jackson-Leach R, Moodie ML, et al. Child and adolescent obesity: part of a bigger picture. Lancet 2015;385 (9986):2510-2520 https://linkinghub.elsevier.com/retrieve/pii/ S0140673614617463 cited 2019Jul15 [Internet]

4 Yavuz E, Morawski K, Telischi FF, et al. Simultaneous measurement of electrocochleography and cochlear blood flow during cochlear hypoxia in rabbits. J Neurosci Methods 2005;147(01): 55-64 http://www.ncbi.nlm.nih.gov/pubmed/16054516 cited 2018Dec23 [Internet]

5 Üçler R, Turan M, Garça F, Acar İ, Atmaca M, Çankaya H. The association of obesity with hearing thresholds in women aged 1840 years. Endocrine 2016;52(01):46-53

6 Sahoo K, Sahoo B, Choudhury AK, Sofi NY, Kumar R, Bhadoria AS. Childhood obesity: causes and consequences. J Family Med Prim Care 2015;4(02):187-192

7 Dhanda N, Taheri S. A narrative review of obesity and hearing loss. Int J Obes 2017;41(07):1066-1073. Doi: 10.1038/ijo.2017.32; [Internet]

8 Keskin M, Kurtoglu S, Kendirci M, Atabek ME, Yazici C. Homeostasis model assessment is more reliable than the fasting glucose/insulin ratio and quantitative insulin sensitivity check index for assessing insulin resistance among obese children and adolescents. Pediatrics 2005;115(04):e500-e503 http://pediatrics.aappublications.org/cgi/doi/10.1542/peds.2004-1921 cited 2019Jul15 [Internet]

9 Behrman RE, Kliegman RM JH. (eds).Nelson Textbook of Pediatrics. In: Pediatrics. 18th ed. saunders; 2007:589

10 Moore DR, Edmondson-Jones M, Dawes P, et al. Relation between Speech-in-Noise Threshold, Hearing Loss and Cognition from 4069 Years of Age. [cited 2020 May 2]; Available from: www. ukbiobank.ac.uk

11 Hwang JH, Wu CC, Hsu CJ, Liu TC, Yang WS. Association of central obesity with the severity and audiometric configurations of agerelated hearing impairment. Obesity (Silver Spring) 2009;17(09): 1796-1801. Doi: 10.1038/oby.2009.66 [Internet]

12 Fransen E, Topsakal V, Hendrickx J-J, et al. Occupational Noise, Smoking, and a High Body Mass Index are Risk Factors for Agerelated Hearing Impairment and Moderate Alcohol Consumption is Protective: A European Population-based Multicenter Study. J Assoc Res Otolaryngol [Internet]. [cited 2018 Dec 23]; Available from: https://www.ncbi.nlm.nih.gov/pmc/articles/PMC2492985/ pdf/10162_2008_Article_123.pdf

13 Lalwani AK, Katz K, Liu YH, Kim S, Weitzman M. Obesity is associated with sensorineural hearing loss in adolescents. Laryngoscope 2013;123(12):3178-3184

14 Shargorodsky J, Curhan SG, Eavey R, Curhan GC. A prospective study of cardiovascular risk factors and incident hearing loss in men. Laryngoscope 2010;120(9, S3)1887-1891 http://doi.wiley. com/10.1002/lary.21298 cited 2018Dec23 [Internet]

15 Kim TS, Park SW, Kim DY, Kim EB, Chung JW, So HS. Visceral adipose tissue is significantly associated with hearing thresholds in adult women. Clin Endocrinol (Oxf) 2014;80(03):368-375 
16 Hwang J-H, Hsu C-J, Yu W-H, Liu T-C, Yang W-S. Diet-induced obesity exacerbates auditory degeneration via hypoxia, inflammation, and apoptosis signaling pathways in $\mathrm{CD} / 1$ mice. LópezLluch G, editor. PLoS One [Internet]. 2013 Apr 26 [cited 2018 Dec 23];8(4):e60730. Available from: https://dx.plos.org/10.1371/ journal.pone.0060730

17 Frederiksen TW, Ramlau-Hansen CH, Stokholm ZA, et al. Atherogenic risk factors and hearing thresholds. Audiol Neurotol 2014; 19(05):310-318

18 Koba S, Hirano T. [Dyslipidemia and atherosclerosis]. Nihon Rinsho 2011;69(01):138-143

19 Hwang JH. Role of Obesity on the Prognosis of Sudden Sensorineural Hearing Loss in Adults. Otolaryngol Head Neck Surg 2015; 153(02):251-256

20 Bülent Satar YÖHSSHÖ Ultrastructural Effects of Hypercholesterolemia on the Cochlea. Otol \&amp [Internet]. 2001 Nov 1 [cited 2018 Dec 23];22(6):786-9. Available from: https://insights.ovid. com/crossref?an $=00129492-200111000-00012$

21 Seob Lee J, Hyun Kim D, Jeong Lee H, et al. Lipid Profiles and Obesity as Potential Risk Factors of Sudden Sensorineural Hearing Loss. 2015 [cited 2018 Dec 23]; Available from: http://dx.doi.org/ 10.5061/dryad.r67t6

22 Evans MB, Tonini R, Shope CD, et al. Dyslipidemia and auditory function. Otol Neurotol 2006;27(05):609-614 http://www.ncbi. nlm.nih.gov/pubmed/16868509 cited 2018Dec23 [Internet]
23 Ballesteros F, Tassies D, Reverter JC, Alobid I, Bernal-Sprekelsen M. Idiopathic sudden sensorineural hearing loss: classic cardiovascular and new genetic risk factors. Audiol Neurotol 2012;17(06): 400-408 http://www.ncbi.nlm.nih.gov/pubmed/22948415 cited 2018Dec23 [Internet]

24 Zivkovic-Marinkov E, Milisavljevic D, Stankovic M, Zivic M, Bojanovic $M$. Is there a direct correlation between the duration and the treatment of type 2 diabetes mellitus and hearing loss? Hippokratia 2016;20(01):32-37

25 Frisina ST, Mapes F, Kim S, Frisina DR, Frisina RD. Characterization of hearing loss in aged type II diabetics. Hear Res 2006;211(12):103-113 http://www.ncbi.nlm.nih.gov/pubmed/16309862 cited 2018Dec23 [Internet]

26 Wang C, Chan JSY, Ren L, Yan JH. Obesity Reduces Cognitive and Motor Functions across the Lifespan. Neural Plast 2016; 2016:2473081

27 Clegg J, Hollis C, Mawhood L, Rutter M. Developmental language disorders-a follow-up in later adult life. Cognitive, language and psychosocial outcomes. J Child Psychol Psychiatry 2005;46(02): 128-149

28 Smith J, Wang J, Grobler AC, Lange K, Clifford SA, Wake M. Hearing, speech reception, vocabulary and language: population epidemiology and concordance in Australian children aged 11 to 12 years and their parents. BMJ Open 2019;9(Suppl 3): 85-94 